Mateus Habermann'

Nelson Gouveia"

\section{Justiça Ambiental: uma abordagem ecossocial em saúde}

\section{Environmental Justice: an ecossocial health approach}

\section{RESUMO}

Discute-se a questão do risco das tecnologias contemporâneas em face do atual paradigma tecnológico, a sua percepção e tolerabilidade, assim como sua distribuição desigual na sociedade. A hipótese fundamental que enfatiza a Justiça Ambiental refere-se aos perigos desproporcionalmente ou injustamente distribuídos entre grupos social e economicamente mais vulneráveis, geralmente pobres e minorias, acarretados pelos riscos ambientais relativos à vida moderna. Assim, vulnerabilidade e os diversos níveis de privação agem como propulsores dos níveis diferenciais em saúde entre os grupos populacionais. Embora Justiça Ambiental tenha sido observada inicialmente como movimento popular nos Estados Unidos, seus princípios indicaram compatibilidade em escalas geográficas global e local. Desta forma, o objetivo do estudo foi compreender como os riscos da tecnologia contemporânea afetam desigualmente a população à luz da Justiça Ambiental.

DESCRITORES: Justiça Social. Iniqüidade Social. Riscos Ambientais. Vulnerabilidade Social. Saúde Ambiental.

\begin{abstract}
The paper addresses the risk of contemporary technologies in the light of our current technological paradigm, its perception and tolerability, as well as its unequal distribution across society. The fundamental hypothesis, which emphasizes Environmental Justice, refers to hazards that are disproportionately or unjustly distributed across more socially and economically vulnerable groups, which are generally the poor and the minorities affected by the environmental risks posed by modernity. Therefore, vulnerability and the different levels of deprivation act as drivers of the different levels of health across population groups. Although Environmental Justice has initially been observed as a grassroots movement in the United States, its principles showed compatibility with global and local geographical scales. Therefore, the aim of the study was to understand how the risks of contemporary technologies unequally affect the population under the perspective of Environmental Justice.
\end{abstract}

Mateus Habermann

Departamento de Medicina Preventiva Faculdade de Medicina da USP - FMUSP

Av. Dr. Arnaldo 455

01246-903 São Paulo, SP, Brasil

E-mail: mathab@usp.br

DESCRIPTORS: Social Justice. Social Inequity. Environmental Risks. Social Vulnerability. Environmental Health. 


\section{INTRODUÇÃO}

A humanidade sempre enfrentou perigos diversos, sejam aqueles involuntários decorrentes de catástrofes naturais - terremotos, erupções vulcânicas, furacões - ou associados às guerras, às vicissitudes da vida cotidiana ou ainda os voluntários, decorrentes do estilo de vida. Entretanto, esses eventos não eram denominados riscos, eram referidos como perigos, fatalidades, hazards ou dificuldades, mesmo porque a expressão risco ainda não existia nos vocabulários das línguas indo-européias, seu significado emergiu nos séculos XVI e XVII juntamente com a formação dos estados-nações. ${ }^{28}$

Considera-se o risco uma forma de se relacionar com o futuro ${ }^{28}$ expressa pela probabilidade de que uma determinada ameaça ocorra, causando danos aos seres humanos e a seu bem-estar. ${ }^{26}$ Ainda, o risco pode ser conceituado em função das suas formas de contato, das características das populações expostas, suas conseqüências e também da natureza da ameaça - agente físico, químico ou biológico ou um conjunto de condições que possuam o potencial de causar danos. ${ }^{13}$

O risco fundamenta a existência dos indivíduos, organizações e sociedades ${ }^{24} \mathrm{e}$ vem sendo amplamente discutido em conseqüência de acidentes industriais, aumento da poluição ambiental, constatação do aquecimento global, dentre outros fatores. A ocorrência desses riscos pode trazer várias conseqüências para as pessoas como stress, agravos, doenças, morte, danos à propriedade, perda econômica e ainda implicações ao meio ambiente, com perda de flora e fauna, poluição e desequilíbrio ambiental. ${ }^{26} \mathrm{~A}$ partir disso, questões como segurança pública, gerenciamento e comunicação de riscos vieram à tona, bem como o aumento da intolerância ao risco.

A distribuição desses riscos na sociedade pode ser comparada com a distribuição social da riqueza. Dessa forma, os conflitos provenientes da carência são substituídos por problemas e conflitos oriundos da produção e repartição dos riscos, o que Beck ${ }^{4}$ descreve como uma transição da sociedade de classes para a sociedade dos riscos. Nessa transição, a natureza dos riscos passa a ser mais complexa, produto do desenvolvimento da ciência e da tecnologia. As questões de desenvolvimento e aplicação de tecnologias são substituídas por questões de gestão política e científicas dos riscos gerados. ${ }^{4}$

O efeito secundário disso é a socialização das destruições e ameaças à natureza, com agravamento de contradições, conflitos econômicos, sociais e políticos: condições naturais de vida se transformam em ameaças médicas, sociais e econômicas para os seres humanos, com desafios novos às instituições sociais e políticas da sociedade mundial industrializada. ${ }^{4}$

Os riscos, assim como as ações humanas, se dão no espaço geográfico e, da mesma forma, este espaço age como um meio para que estes ocorram. ${ }^{23}$ A produção desse espaço acrescenta valores e significados ao uso da terra e estes usos representam a forma física do mundo social e a base para a prática regulatória, traduzida por meio da ocupação e uso do solo. ${ }^{15,23,27} \mathrm{O}$ espaço geográfico visualizado como agente e produto da sociedade reflete a reprodução das desigualdades, entre as quais se inserem formas díspares de exposição aos riscos ambientais por meio dos diversos estratos sociais, culturais, étnicos, entre outros.

Nesse espaço socialmente produzido pode estar presente um conjunto de poluentes, oriundos de fontes químicas, tais como os produtos de combustão (CO, $\mathrm{NO}_{2}$ ), pesticidas e agrotóxicos, ou aqueles oriundos de fontes biológicas como vírus e bactérias ou ainda de fontes físicas como os ruídos, radiações ionizantes e não ionizantes.

Assim como a proximidade a determinados elementos pode trazer resultados positivos auxiliando na melhoria da qualidade de vida, elementos geradores de poluentes trazem resultados negativos, sendo evitados por ocasionarem impactos tanto ao homem em si, como às suas propriedades, uma vez que geram riscos. Portanto, a localização do homem no espaço geográfico e social permite a este se encontrar em maior ou menor segurança.

Diante disso, o presente artigo teve por objetivo compreender como os riscos da tecnologia contemporânea afetam desigualmente a população à luz da Justiça Ambiental. Do mesmo modo, o artigo discute o tema Justiça Ambiental como uma abordagem importante para estudos ecossociais no campo da saúde pública.

Foi realizada uma busca bibliográfica em bases de dados on-line cadastradas pela Coordenação de Aperfeiçoamento de Pessoal de Nível Superior (Capes), de 1990 até 2007, utilizando-se como palavras-chave "Justiça Ambiental" ou "Environmental Justice”. No Brasil, entretanto, devido ao seu ineditismo, constatou-se uma escassez de pesquisas empíricas referentes à Justiça Ambiental, encontrando-se apenas discussões teóricas.

\section{SIGNIFICADOS ATRIBUÍDOS AO RISCO}

A aceitabilidade de um determinado risco depende do benefício que está em jogo, assim como o número de atores envolvidos no processo (número de expostos). Slovic ${ }^{25}$ acredita que o risco é inerentemente subjetivo e depende de julgamentos individuais, sendo influenciados por diversos fatores sociais, psicológicos e culturais.

A sociedade moderna tende a admitir riscos de menor conseqüência e maior probabilidade (ex. acidente automobilístico) em detrimento dos riscos de alta conseqüência e baixa probabilidade (ex. acidente em usina nuclear). Esses tipos variados de percepção da sociedade compõem um fenômeno denominado amplificação social do risco. ${ }^{12}$ 
Desse modo, a pesquisa de um determinado risco deve definir o tipo, número e qualidade dos fatores que influenciam a opinião dos indivíduos e das avaliações sobre risco dentro de seus valores, motivações, objetivos e benefícios. Estes fatores contribuem para o entendimento, aceitabilidade e controvérsias, servindo como ferramenta de gerenciamento dos mesmos. ${ }^{18}$

Portanto, a consideração por parte do poder público da percepção de riscos na sociedade é importante, pois valores como eqüidade e potencial de catástrofe podem se integrar nas análises e decisões políticas e não somente os aspectos técnico-científicos, que consideram apenas benefícios econômicos, custos e eficácia.

A partir daí surgem questões: há acesso irrestrito das populações afetadas às informações que esclareçam sobre os possíveis danos às quais estão expostas? As populações têm direito de reivindicar e modificar o destino das políticas a que foram sujeitas? Os riscos estão distribuídos eqüitativamente, espacialmente e socialmente, ou apenas alguns extratos se beneficiam ou se prejudicam com determinado atributo e o seu risco gerado?

\section{SEGREGAÇÃO ESPACIAL E RISCOS}

A localização dos objetos, eventos e atividades no espaço, inclusive dos riscos ambientais são representadas essencialmente pela estrutura de classes de uma coletividade. ${ }^{24}$ Por conseguinte, a distribuição desproporcional da poluição e da degradação ambiental no espaço tem sido foco de crescente interesse e manifestações em diversas partes do mundo.

A organização espacial das cidades faz com que elas atraiam e também agravem a situação de pobreza, sendo o espaço geográfico um fator ativo para a ocorrência de tal fato, assim como a economia, a cultura e as instituições. Desta forma, o espaço urbano é diferentemente ocupado em função das classes em que se divide a sociedade. ${ }^{22}$ Áreas onde existem fatores de risco são preteridas pelas camadas de renda superior, por isso se pressupõe que sejam ocupadas pela população de baixa renda. ${ }^{31}$ Portanto, a renda é um fator que influencia a localização das pessoas no espaço, na medida em que a população de menor poder aquisitivo, sem opção, está sujeita a residir em locais considerados danosos e mais expostas a riscos, comparado às populações de renda superior.

Neste caso, locais danosos podem ser comparados às externalidades propostas por Harvey, ${ }^{11}$ produtos adicionais das atividades urbanas, que geram efeitos sobre outros elementos e imediatamente ou indiretamente afetam o bem-estar dos indivíduos. Essas externalidades, somadas à lógica do mercado imobiliário e da renda da terra, naturalizam o fato de que bairros pobres se desenvolvam na proximidade de indústrias poluidoras, por exemplo, e estes locais sejam os mais negligenciados pelo poder público. ${ }^{1}$
Segundo Soja, ${ }^{27}$ uma segmentação e fragmentação mais profundas estão ocorrendo na sociedade, com uma valorização mais pronunciada entre trabalhadores de qualificações e salários mais elevados em contraposição aos trabalhadores de baixa qualificação e salário. Assim, segregações residenciais e vulnerabilidade socioeconômica estão cada vez mais manifestas.

O grau de vulnerabilidade socioeconômica está normalmente associado à exposição diferencial aos riscos e designa a maior ou menor susceptibilidade de pessoas, lugares, infra-estruturas ou ecossistemas a sofrerem algum tipo particular de agravo, podendo ser associado a fatores individuais, político-institucionais e sociais ou a somatória destes. ${ }^{1}$ A história de distribuição dos riscos na sociedade tem mostrado padrão semelhante à distribuição de riquezas no sistema de classes, mas de modo contrário, ou seja, mais riscos para os mais pobres, ${ }^{4}$ de forma que a incorporação do tema da vulnerabilidade leva ao desenvolvimento de metodologias que tenham como referência estratégias de investigação e avaliação territorializadas. Esta territorialização permite contextualizar a análise científica e recuperar as dimensões sociais, econômicas e éticas inerentes que permeiam a questão ambiental.

Embora ainda se saiba pouco sobre a interação entre riscos sociais e ambientais para a saúde, pesquisadores vêm examinando como as condições socioeconômicas afetam o bem-estar e a saúde das populações e são representadas no espaço geográfico. A segregação expõe as comunidades a riscos ambientais que amplificam a vulnerabilidade individual e coletiva aos efeitos tóxicos dos poluentes. Essa dinâmica pode explicar em parte as disparidades de saúde existentes. ${ }^{17}$

O poder público possui um papel primordial nas questões de desigualdade e vulnerabilidade, pois onde a lógica econômica de eficiência e rentabilidade se sobrepõe à lógica do serviço público, as condições sociais e ambientais do território são suficientemente desreguladas para permitir a ocorrência de iniqüidades. ${ }^{30}$

O Estado, portanto, age seletivamente em relação aos diversos atores da economia, por meio da repartição das infra-estruturas no espaço e pela escolha daqueles que beneficiam um determinado setor da produção e da população, ou seja, acaba decidindo a localização das instituições e dos homens sobre o território. Um meio para que isso ocorra, por exemplo, são as leis de zoneamento das cidades ao determinarem quais tipos de usos e de densidades de terra podem ocorrer em cada porção das áreas urbanas. ${ }^{23}$

\section{MOVIMENTO DE JUSTIÇA AMBIENTAL}

O movimento de Justiça Ambiental resulta das desigualdades crescentes na sociedade e vem atraindo atenção ao papel que as políticas públicas, junto com forças de mercado e outros fatores podem provocar na geração 
ou exacerbação de iniqüidades frente aos riscos. ${ }^{16}$ Tal movimento volta-se ao interesse sobre a distribuição de perigos ambientais entre os diversos estratos sociais. A hipótese central que enfatiza esta literatura refere-se aos perigos à saúde desproporcionalmente distribuídos entre grupos sociais mais vulneráveis, geralmente pobres e minorias, acarretados pelos riscos ambientais. ${ }^{5}$

Clayton $^{6}$ atribui três razões principais para explicar porque a justiça (“fairness”) tornou-se um tema relevante nos últimos anos: percepção de que os recursos naturais não são renováveis, crescimento da consciência por parte da sociedade sobre suas responsabilidades no impacto destrutivo provocado ao meio ambiente e finalmente a distribuição injusta de um risco ambiental relacionado a grupos específicos com identidades consolidadas (de renda, cultura ou etnia), esta última é o foco principal da temática relacionada à Justiça Ambiental.

Movimentos por Justiça Ambiental começaram a ser organizados nos Estados Unidos, como iniciativa de cidadãos depois do caso de contaminação química em Love Canal, Niagara (Nova York) em 1978, quando moradores de um conjunto habitacional de baixa renda descobriram que suas casas estavam junto a um canal aterrado com dejetos químicos industriais e bélicos. Esses movimentos permaneceram em torno de um argumento comum: as cargas ambientais, como a proximidade a locais perigosos, tendem a ser desigualmente atribuídas a pobres e minorias em geral.

A partir daí o US General Accounting Office conduziu uma pesquisa e comprovou que a distribuição espacial dos depósitos de resíduos químicos perigosos, bem como a localização de indústrias muito poluentes, se sobrepunham e acompanhavam a distribuição territorial de etnias pobres nos Estados Unidos. ${ }^{1} \mathrm{Na}$ região que compreende o sudeste dos Estados Unidos foram encontrados quatro aterros de rejeitos perigosos, três deles estavam localizados em comunidades afro-americanas, apesar dos negros serem apenas um quinto da população da região.

Na Califórnia, a zona de ocupação latina à leste de Los Angeles e de Kettleman (comunidade rural com aproximadamente 95\% de latinos) também é alvo destas escolhas. O mesmo se diz dos povos indígenas: mais de 36 reservas indígenas foram objetos da localização de aterros e incineradores: em 1991, os Choctaws da Filadélfia conseguiram derrotar um projeto de alocar um aterro de lixo de 188 hectares em suas terras. ${ }^{1}$

Pressionado pelos movimentos populares, o governo federal americano e algumas legislações estaduais estabeleceram políticas voltadas à proteção dos direitos, por exemplo, direito à informação sobre instalações que existem ou existirão em uma vizinhança ("Right to know Act”), a que diz respeito aos procedimentos para descontaminação de locais contaminados ("Clean-up
$A c t$ ”) e a criação de fundos direcionados às comunidades afetadas, dando meios financeiros para contratar serviços técnicos e processuais. ${ }^{1}$

Embora a Justiça Ambiental seja observada inicialmente como um movimento popular dos Estados Unidos, seus princípios desde seu surgimento indicaram a compatibilidade imediata e em longo prazo desta com extensões ecológicas de sustentabilidade em todas as escalas da geografia: do global ao local. ${ }^{29}$

O movimento de Justiça Ambiental destaca o déficit de responsabilidade do Estado e os mecanismos políticos e econômicos que tornam os sujeitos vulneráveis, uma vez que as definições mais correntes de vulnerabilidade enfatizam os sujeitos sociais em vez dos processos que os tornam vulneráveis. Uma alternativa para isso seria definir os vulneráveis como vítimas de uma exposição desigual, determinando e interrompendo os processos decisórios que impõem riscos aos mais desprotegidos, tais como decisões sobre a localização de equipamentos que se utilizam de tecnologia danosa ao meio ambiente e à saúde, dinâmicas desiguais do mercado e outras. ${ }^{1}$

Os estudos sobre Justiça Ambiental iniciaram com apreciações prévias sobre existência de desigualdades e passaram a buscar provas em estudos de casos que documentassem injustiças. Após duas décadas de pesquisa, as pesquisa relacionadas ao tema enfrentaram problemas metodológicos sobre como quantificar medidas (indicadores) que empiricamente reflitam vulnerabilidade a partir do bem-estar econômico e a situação de grupos ou comunidades situadas próximas a fontes danosas à saúde. ${ }^{32}$

Estes indicadores devem refletir a oportunidade (econômica, organizacional e social) das pessoas em participarem na distribuição de recursos, tanto a nível individual quanto coletivo, por exemplo, como níveis de desemprego e renda influenciam na quantidade de recursos adquiridos por um domicílio. ${ }^{32}$ Informações de inquéritos governamentais, como estudos amostrais e censos, são ferramentas que podem ser utilizadas para estimar e comparar a renda de grupos de diversas regiões com características similares.

Clayton $^{6}$ pontua diferentes formas que a Justiça Ambiental pode assumir:

- Eqüidade - grupos de pessoas ou países consomem mais recursos naturais em detrimento de outros, mais afetados pela poluição ambiental. Isso ocorre devido ao baixo poder político e reivindicatório destas populações. A busca por eqüidade visa assegurar que nenhum grupo sofra desproporcionalmente os efeitos da degradação ambiental.

- Questões procedimentais - refere-se à oportunidade de participação de todas as partes interessadas nos 
processos decisórios, o que geralmente não acontece em regulações ambientais. Não é concedida chance para os envolvidos opinarem que muitas vezes encontram-se desprovidos de poder social e são diretamente afetados pelos impactos negativos.

O movimento por Justiça Ambiental tem atraído cada vez mais atenção no meio acadêmico, pois envolve inter-relações do espaço geográfico visando criar eqüidade e justiça. Algumas de suas definições apresentam os seguintes princípios:

“Justiça Ambiental se baseia no princípio de que todas as pessoas têm o direito de estar protegidas de poluição ambiental, viver e desfrutar de um ambiente limpo e saudável. A proteção igual e o envolvimento significativo de todas as pessoas a respeito do desenvolvimento, implementação e o cumprimento de leis ambientais, regulações e políticas e a distribuição eqüitativa de benefícios ambientais" (Commonwealth of Massachusetts p.2). ${ }^{2}$

Porto $^{21}$ define Justiça Ambiental como:

“Conjunto de princípios e práticas que asseguram que nenhum grupo social, seja ele étnico, racial, de classe ou gênero, suporte uma parcela desproporcional das conseqüências ambientais negativas de operações econômicas, decisões políticas e de programas governamentais, assim como da ausência ou omissão de tais políticas, assegurando assim, tanto o acesso justo e eqüitativo aos recursos ambientais do país, quanto o acesso amplo às informações relevantes que lhes dizem respeito".

Nas conceituações se percebe como as externalidades negativas defendidas por Harvey ${ }^{11}$ aparecem como auxiliar da promoção e sustentação da segregação espacial urbana, pois são atribuídas aos mais pobres e às áreas onde residem. Porto ${ }^{21}$ enfatiza que os grandes investimentos e negócios realizados se apropriam dos recursos dos territórios concentrando renda e poder nas mãos de poucos, ao mesmo tempo em que atingem a saúde e integridade de seus habitantes e ecossistemas.

\section{JUSTIÇA AMBIENTAL NO BRASIL}

No Brasil, além do desemprego, desproteção social e precarização do trabalho, grande parte da população encontra-se desproporcionalmente exposta a riscos ambientais, seja nos locais de trabalho, de moradia ou no ambiente em geral. Porém, o tema da Justiça Ambiental é ainda incipiente no País, pois os casos de exposição a riscos são pouco conhecidos e divulgados, tendendo a se tornarem problemas crônicos, sem solução. Devido à ampla gama de desigualdades sociais existentes, a exposição desigual aos riscos fica obscurecida pela extrema pobreza e as péssimas condições gerais de vida a ela associada.
O marco inicial de divulgação da Justiça Ambiental no Brasil foi a coleção intitulada "Sindicalismo e Justiça Ambiental” de 2000, da Central Única dos Trabalhadores do Rio de Janeiro. A finalidade era incitar a discussão sobre a responsabilidade e o papel dos trabalhadores e suas entidades representativas na defesa de um meio ambiente urbano sustentável e com qualidade de vida a todos os seus moradores, entendendo que os recursos ambientais são bens coletivos, cujos modos de apropriação e gestão são públicos. ${ }^{1}$

Em 2001 foi realizado o Colóquio Internacional sobre Justiça Ambiental, Trabalho e Cidadania, na Universidade Federal Fluminense, em Niterói (RJ). Esta foi uma das primeiras iniciativas no Brasil para discutir enfoques teóricos e implicações políticas da proposta de Justiça Ambiental, fazendo o histórico e avaliação de casos de injustiça ambiental no País, da experiência dos sindicatos e a construção de agenda, parcerias e coalizão nacional e internacional.

Na ocasião, foi criada a Rede Brasileira de Justiça Ambiental com objetivo de reverter a fragmentação e o isolamento dos vários movimentos, pressionar órgãos governamentais e empresas para que divulguem informações ao público, apoiar pesquisas voltadas para os temas da Justiça Ambiental, desenvolver cooperação científica, da troca de informação sobre normas e padrões ambientais. ${ }^{1}$

\section{TRABALHOS RELACIONADOS À JUSTIÇA AMBIENTAL}

Existem muitos estudos sobre distribuição desigual de fenômenos positivos e negativos associados com grupos culturais, étnicos e sociais, porém nem todos eles explicitam a temática da Justiça Ambiental. A "Escola de Chicago", nas primeiras décadas do século $\mathrm{XX}$, foi precursora em demonstrar associações entre $\mathrm{o}$ padrão espacial das cidades e sua ordem social, o que se denominou ecologia humana. ${ }^{20}$

A ecologia humana tem um foco social que se manifesta em padrões ecológicos e utiliza-se de termos como comunidade, divisão e especialização de atividades, concentração em ramos de atividade, dominância, distribuição ecológica, na qual se incluem noções como mobilidade, segregação, dispersão, centralização entre outras. Tal abordagem serviu de base para interpretar as distribuições espaciais de prostituição, ocorrência de suicídios, segregação de grupos determinados, guetos, delinqüência, entre outros. ${ }^{20}$

Somente nas últimas décadas, as pesquisas começaram a se preocupar com o meio ambiente e os riscos oriundos de poluentes e sua repartição entre a sociedade. Um estudo precursor que apontava iniqüidades ambientais, relacionando riscos ambientais à renda e grupos vulneráveis foi o de Mccaull ${ }^{29}$ em 1976, mostrando disparidades 
na poluição do ar a partir de mapas da área urbana de Washington (Estados Unidos). O trabalho indicou que as chances de exposição a ar de qualidade ruim são maiores para negros e pessoas na pobreza, em sub ocupações ou residindo em distritos de baixa renda.

Vogt \& Sorensen ${ }^{32}$ verificaram a prevalência de exposição e a caracterização da população de oito comunidades do entorno de instalações militares que estocam armamentos químicos e munições dos Estados Unidos. Os resultados mostraram que o percentual de população negra residindo em áreas mais próximas a estas instalações era maior que a média do estado onde as comunidades se encontravam.

Na Carolina do Norte (Estados Unidos), Wing et a ${ }^{33}$ analisaram a localização e concentração de poluentes e odores ofensivos derivados da criação de suínos em relação a características raciais, econômicas e da água em áreas vizinhas. Houve 7,2 vezes mais emissões de restilo nos quintis mais altos de pobreza comparados aos mais baixos. As emissões de restilo são ainda aproximadamente cinco vezes mais comuns nos três quintis mais altos do percentual de não brancos quando comparados com mais baixos. O excesso de emissões é ainda maior em áreas com altos percentuais de pobreza e população não branca.

Por meio de modelos de dispersão, Dolinoy \& Miran$\mathrm{da}^{8}$ desenvolveram métodos para estimar emissões de poluentes de uma indústria representativa de Durham County, Carolina do Norte. A análise multivariada indicou disparidades de renda e raça entre aqueles que residiam nos pontos mais afetados pela poluição, comparado à população menos exposta.

Harner et al $^{10}$ desenvolveram e testaram índices de medição de Justiça Ambiental em cidades do Colorado que poderiam ser aplicáveis em qualquer cidade dos Estados Unidos, baseados em testes estatísticos. As fontes de ameaças ambientais consideradas incluíram locais de aterros, estocagem e depósitos de produtos tóxicos. Variáveis demográficas usadas para medir Justiça Ambiental incluíram renda média familiar, percentual de não brancos e percentual de população abaixo da linha de pobreza. Os índices criados analisam áreas que podem estar mais vulneráveis a ameaças tóxicas do que outras e investigam a subordinação de populações pobres e minorias viverem em áreas altamente tóxicas.

Por meio das características raciais e socioeconômicas dos setores censitários de Maryland nos Estados Unidos, Apelberg et $\mathrm{al}^{3}$ avaliaram as disparidades no risco de câncer estimado para exposição a ar tóxico emitidos por fontes poluentes entre os diversos estratos sociais e étnicos. Setores censitários nos quartis definidos pelo percentual mais alto de negros tiveram um risco três vezes maior do que aqueles dos quartis mais baixos (IC 95\% 2,0-5,0), por outro lado o risco decresceu quando o percentual de população branca aumentava $(p<0,001)$. Setores censitários nos quartis mais baixos de nível socioeconômico foram de 10 a 100 vezes mais prováveis de estarem em alto risco do que aqueles nos quartis mais altos.

Gouldson $^{9}$ avaliou as variações de características socioeconômicas de comunidades nos Estados Unidos e União Européia onde refinarias de petróleo eram localizadas, para isso utilizou dados de desemprego, renda per capita e densidade populacional. Isto permitiu examinar se as emissões de poluentes das refinarias eram maiores em áreas mais carentes. Os resultados indicaram que havia correlações entre níveis mais elevados de emissões de poluentes das refinarias localizadas em áreas com níveis de renda mais baixos e maiores níveis de desemprego.

A cidade de Pueblo, Colorado (Estados Unidos), foi caracterizada pelo uso da terra da cidade em termos de metais pesados e a distribuição da população. ${ }^{7}$ Amostras de solo de diferentes partes de Pueblo foram retiradas para avaliar a concentração de metais pesados: arsênio (As), cádmio (Cd), mercúrio (Hg) e chumbo (Pb). As comunidades também foram categorizadas em termos de condições socioeconômicas e demográficas. Elevadas concentrações de chumbo e cádmio estavam presentes em comunidades de baixa renda onde se incluíam negros e hispânicos.

\section{CONSIDERAÇÕES FINAIS}

O presente artigo procurou discutir como o paradigma de sociedade contemporânea e os riscos gerados por esta podem afetar a si própria e de forma desigual. Até que ponto o atual modelo econômico pautado no consumismo e no imediatismo garantirá um futuro seguro com qualidade de vida para todos e para as futuras gerações? A população demanda por justiça em todos os sentidos, percebe os impactos gerados pelo desenvolvimento e a ampla maioria participa de forma marginal.

A distribuição dos riscos entre a população, não apenas socialmente, mas espacialmente, torna a temática da Justiça Ambiental uma proposta metodológica importante aos estudos de base espacial, principalmente com a facilidade trazida pela utilização dos sistemas de informação geográfica. É mais uma abordagem de pesquisa à disposição daqueles que buscam a melhoria da qualidade de vida e de uma sociedade mais justa e sustentável. Por conseguinte, o artigo procurou apresentar estudos já realizados em outros países servindo como motivação para sua aplicação no Brasil.

As pesquisas de cunho territorial em saúde teriam grande potencial para renovar e expandir seu alcance social se estas se solidarizassem com as populações pobres e marginalizadas, assim como os movimentos sociais renovariam e ampliariam o alcance de suas lutas, se a eles fosse incorporada a questão da Justiça Ambiental. 


\section{REFERÊNCIAS}

1. Acselrad H, Herculano S, Padua JA. Justiça Ambiental e a cidadania. Rio de Janeiro: Relume Dumará; 2004.

2. Agyeman J, Evans B. 'Just sustainability': the emerging discourse of environmental justice in Britain? Geogr J. 2004;170(2):155-64. DOI: 10.1111/j.00167398.2004.00117.x

3. Apelberg BJ, Buckley TJ, White RH. Socioeconomic and racial disparities in cancer risk from air toxics in Maryland. Environ Health Perspect. 2005;113(6):6939

4. Beck U. La Sociedad del riesgo: hacia una nueva modernidad. Barcelona: Paidós; 2002.

5. Buzzelli M. Bourdieu does environmental justice? Probing the linkages between population health and air pollution epidemiology. Health Place. 2007;13(1):3-13.

6. Clayton S. Models of Justice in environmental debate. J Soc Issues. 2000;56(3):459-74. DOI: 10.1111/00224537.00178

7. Diawara MM, Litt JS, Unis D, Alfonso N, Martinez L, Crock JG, et al. Arsenic, cadmium, lead, and mercury in surface soils, Pueblo, Colorado: implications for population health risk. Environ Geochem Health. 2006;28(4):297-315. DOI: 10.1007/s10653-0059000-6

8. Dolinoy DC, Miranda ML. GIS modeling of air toxics releases from TRI-reporting and non-TRI-reporting facilities: impacts for environmental justice. Environ Health Perspect. 2004;112(17):1717-24.

9. Gouldson A. Do firms adopt lower standards in poorer areas? Corporate social responsibility and environmental justice in the EU and the US. Area. 2006;38(4):402-12. DOI: 10.1111/j.14754762.2006.00702.x

10. Harner J, Warner K, Pierce J, Huber T. Urban environmental justice indices. Prof Geogr. 2002; 54(3):318-31. DOI: 10.1111/0033-0124.00333

11. Harvey D A. Justiça Social e a cidade. São Paulo: Hucitec; 1980.

12. Kasperson RE, Renn O, Slovic P, Brown HS, Emel J, Goble R, et al. The Social amplification of risk: a conceptual framework. Risk Anal. 1988;18(2):177-87.

13. Kolluru RV, Bartell SM, Pitblado RM, Stricoff RS. Risk assessment and management handbook for environmental, health, and safety professionals. New York: McGraw- Hill; 1996.

14. Kurtz HE. Reflections on the iconography of environmental justice activism. Area. 2005;37(1):7988. DOI: 10.1111/j.1475-4762.2005.00610.x

15. Lefebvre H. The Production of Space. Oxford: Blackwell Publishers; 1991.

16. Minkler M, Vásquez VB, Tajik M, Patersen D. Promoting Environmental Justice through CommunityBased Participatory Research: The Role of Community and Partnership Capacity. Health Educ Behav. 2006;35(1):119-37.
17. Morello-Frosch R, Lopez R. The riskscape and the color line: Examining the role of segregation in environmental health disparities. Environ Res. 2006;102(2):181-96. DOI: 10.1016/ j.envres.2006.05.007

18. Nardocci AC. Gerenciamento Social de Riscos. $R$ Direito Sanit. 2002;3(1):64-77.

19. O'Neill MS, Jerrett M, Kawachi I, Levy JI, Cohen AJ, Gouveia N, et al. Health, wealth, and air pollution: advancing theory and methods. Environ Health Perspect. 2003;111(16):1861-70.

20. Pierson D, organizador. Estudos de Ecologia Humana. São Paulo: Livraria Martins Editora; 1948.

21. Porto MF. Saúde do trabalhador e o desafio ambiental: contribuições do enfoque ecossocial da Ecologia Política e do movimento pela Justiça Ambiental. Cienc Saude Coletiva. 2005;10(4):829-39. DOI: 10.1590/ S1413-81232005000400008

22. Santos M. O espaço do cidadão. 5. ed. São Paulo: Studio Nobel; 2000.

23. Santos M. Da totalidade ao lugar. São Paulo: Edusp; 2005.

24. Sjöberg L, Drottz-Sjöberg BM. Risk Perception. In: Proceedings of International Conference on Radiation and Society: Comprehending Radiation Risk; 1994 Out 24-28; Paris, França: IAEA; 1994. p.29-59.

25. Slovic P. Perception of Risk: Reflections on the psychometric paradigm. In: Krimsky S, Golding D. Social theories of risk. London: Praeger; 1992. p.117-52.

26. Smith K. Environmental hazards: assessing risk and reducing disaster. London: Routledge; 1992. [Routledge Physical Environment series]

27. Soja EW. Post Modern Geographies: the reassertion of space in critical social theory. London: Verso; 1994.

28. Spink MJP. Trópicos do discurso sobre risco: riscoaventura como metáfora na modernidade tardia. Cad Saude Publica. 2001;17(6):1277-311. DOI: 10.1590/ S0102-311X2001000600002

29. Touché GE. Ecological Sustainability, Environmental Justice, and Energy Use: An Annotated Bibliography. J Plan Lit. 2004;19(2):206-26. DOI: 10.1177/0885412204268091

30. Verdeil V. L'Équité Territoriale. Espace Geogr. 1998;3:204-16.

31. Vetter DM, Massena RMR. Quem se apropria dos benefícios líquidos dos investimentos do Estado em infra-estrutura urbana? Uma Teoria de Causação Circular. In: Silva LAM, organizador. Solo Urbano: tópicos sobre o uso da terra. Rio de Janeiro: Zahar; 1982. p.49-78.

32. Vogt BM, Sorensen JH. Environmental Assessment and Social Justice. Oak Ridge: Oak Ridge National Laboratory; 1995.

33. Wing S, Cole D, Grant G. Environmental Injustice in North Carolina's Hog Industry. Environ Health Perspect. 2000;108(3):225-31. DOI: 10.2307/3454438 